\title{
SMOKING
}

\section{Lack of association of group specific component haplotypes with lung function in smokers}

\author{
I Kasuga, P D Paré, J Ruan, J E Connett, N R Anthonisen, A J Sandford
}

Thorax 2003;58:790-793

See end of article for authors' affiliations

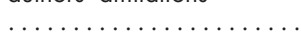

Correspondence to: Dr A J Sandford, McDonald Research Laboratories, St Paul's Hospital, 1081 Burrard

Street, Vancouver, BC Canada V6Z 1Y6;

asandford@mrl.ubc.ca

Revised version received 30 November 2002

Accepted for publication 12 May 2003

\begin{abstract}
Background: Airway inflammation may affect the decrease in lung function that occurs in response to cigarette smoke, and is an important pathological feature in chronic obstructive pulmonary disease (COPD). Group specific component (GC) can act as an inflammatory mediator and may therefore have important influences on the inflammatory reaction in the airway. Several reports have described associations between GC haplotypes and COPD but these remain controversial. In addition, most of these studies were based on a small number of subjects.

Methods: We have studied the contribution of GC haplotypes to the level of lung function in a large cohort of smokers with high or low lung function (mean $\mathrm{FEV}, \%$ predicted 91.8 and 62.6, respectively). The frequency of the three major GC haplotypes (1S, 1F and 2) was investigated in 537 individuals with high lung function and 533 with low lung function.

Results: No significant difference was found in the frequency of any GC haplotype between the high and low lung function groups. There was also no significant difference between the groups in genotype frequency of the two single nucleotide polymorphisms that underlie the haplotypes.

Conclusion: The GC haplotype does not contribute to reduced lung function in this cohort of smokers.
\end{abstract}

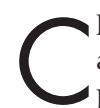
hronic obstructive pulmonary disease (COPD) is characterised by irreversible airflow limitation, increased pulmonary resistance, and hyperinflation of the lung. It is well known that cigarette smoking is the major risk factor for the development of this disease. However, there is considerable variability in the degree of airflow obstruction induced by cigarette smoking, ${ }^{1}$ and only $10-15 \%$ of chronic smokers develop COPD. ${ }^{2}$ These observations indicate that additional risk factors, possibly genetic, contribute to the development of COPD. $^{34}$

Several genes involved in the pathogenesis of COPD have been identified to date, including inflammatory mediator genes. ${ }^{56}$ One of the candidate genes which may also be an inflammatory mediator is group specific component $(G C)$ (also known as vitamin D binding protein). GC is a $55 \mathrm{kDa}$ protein secreted by the liver which is able to bind extracellular actin and endotoxin as well as vitamin D. Besides these functions, GC enhances the neutrophil chemotactic activity of complement component 5a (C5a) peptide and C5a des-Arg produced during the activation of the complement cascade by one to two orders of magnitude. ${ }^{7}$ It also enhances the human monocyte response to C5 derived peptides. ${ }^{8}$ Complement derived peptides are present in the lung under inflammatory conditions ${ }^{910}$ and GC levels have been shown to be increased in bronchoalveolar lavage fluid from smokers compared with non-smokers. ${ }^{11}$ In addition, GC can be converted into a macrophage activating factor (MAF). ${ }^{12} \mathrm{GC}$ may therefore have important influences on the intensity of the inflammatory reaction in the lung.

The GC gene exhibits a number of haplotypes which can be detected by isoelectric focusing. ${ }^{13}$ Of these, the three major haplotypes are $G C$-lfast (1F), GC-1slow (1S), and GC-2 (2), ${ }^{13}$ due to two point mutations in exon 11 of the coding region. Both mutations cause an amino acid substitution. The relationship between $G C$ haplotypes and COPD has been investigated in several white and Japanese populations. A positive association has been reported between the IF haplotype and COPD,${ }^{14}{ }^{15}$ while the 2 haplotype was found to have a protective effect against COPD. ${ }^{14}{ }^{16}$ However, other research- ers have not found any association. ${ }^{18}$ The relationship between the GC haplotype and COPD is therefore not resolved. Moreover, these studies were based on small numbers of subjects.

Lung function, as measured by forced expiratory volume in l second $\left(\mathrm{FEV}_{1}\right)$, normally increases to a maximal value at adulthood, remains stable for 10-15 years, and then declines. ${ }^{19}$ COPD is often assumed to have developed because the patient has experienced an accelerated rate of decline of lung function. However, COPD may also develop even if there is a normal rate of decline, if the patient failed to attain maximal lung function during development, or experienced an early onset of decline. Genetic factors may affect only one of these three mechanisms but few studies have examined these mechanisms specifically.

The Lung Health Study was designed to investigate the impact of early intervention on the course of cigarette induced COPD. We recently investigated GC haplotypes in the participants in the Lung Health Study but found no contribution of any haplotype to the rate of decline in lung function. ${ }^{20}$ Since previous studies have shown associations of $G C$ haplotypes with COPD, the reason for these associations may be related to mechanisms such as reduced maximal lung function or an earlier onset of decline rather than an accelerated rate of decline. If so, this may be reflected by lower lung function at the start of the Lung Health Study. The aim of this study was therefore to investigate the contribution of GC haplotypes to the level of lung function in smokers using the largest number of individuals yet studied. We hoped that this would provide definitive evidence as to the role of $G C$ haplotypes in the pathogenesis of COPD.

\section{METHODS}

\section{Subjects}

Subjects were selected from the participants in the National Heart, Lung and Blood Institute (NHLBI) Lung Health Study. The design of this multicentre randomised clinical trial has been described more extensively elsewhere. ${ }^{21}$ 
Table 1 Characteristics of the high and low lung function groups

\begin{tabular}{|c|c|c|c|}
\hline & $\begin{array}{l}\text { High group } \\
(n=537)\end{array}$ & $\begin{array}{l}\text { Low group } \\
(n=533)\end{array}$ & $\mathrm{p}$ value \\
\hline $\mathrm{F} / \mathrm{M}$ & $183 / 354$ & $203 / 330$ & 0.17 \\
\hline Age (years) & $46.2(0.3)$ & $50.7(0.3)$ & $<0.0001$ \\
\hline Smoking history (pack years) * & $35.3(0.8)$ & $45.1(0.8)$ & $<0.0001$ \\
\hline Baseline $\mathrm{FEV}_{1}(\%$ predicted $\dagger$ & $91.8(0.1)$ & $62.6(0.1)$ & \\
\hline Rate of decline in lung function $\ddagger$ & $-0.6(0.1)$ & $-1.2(0.1)$ & $<0.0001$ \\
\hline Bronchodilator response $(\%) \S$ & $6.2(0.2)$ & $2.7(0.3)$ & $<0.0001$ \\
\hline \multicolumn{4}{|c|}{$\begin{array}{l}\text { Values for continuous variables are mean (SE). } \\
\text { * Number of packs of cigarettes smoked per dayxnumber of years smoking. } \\
\text { †Lung function at the start of the study. } \\
\text { †Change in lung function per year over a } 5 \text { year period measured as } \% \text { predicted } \mathrm{FEV}_{1} \text {. } \\
\text { §Percentage change in FEV, from baseline in response to a bronchodilator. } \\
\text { FEV }=\text { forced expiratory volume in } 1 \text { second. }\end{array}$} \\
\hline
\end{tabular}

A total of 5887 male and female smokers aged 35-60 years with spirometric signs of early COPD were recruited. From this cohort we had previously selected the 303 individuals with the highest rate of decline in lung function and the 325 with the slowest rate of decline in lung function. Of those who remained, we selected for the present study the 500 individuals who had the highest post-bronchodilator level of lung function at the start of the Lung Health Study and an equivalent number of individuals who had the lowest level of lung function. The range of $\mathrm{FEV}_{1} \%$ predicted in the high lung function group was 88.9-99.6 and in the low lung function group was 47.1-67.0. Since 140 individuals from our previous study had lung function in one of these ranges, they were included in the present study. In total, 1140 DNA samples were selected and, of those, 1115 samples were successfully amplified. Of this group, 1070 were white and 45 were from other ethnic groups. Because of the potential for type I error, we studied the white patients only. Other ethnic groups were of insufficient sample size and were excluded from the study. Of the white patients, the high lung function group contained 537 individuals and the low lung function group contained 533. Exclusion criteria included serious illness such as cancer, heart disease, or other important conditions that required medical treatment.

\section{Genotyping}

The subjects were genotyped for the three GC haplotypes by polymerase chain reaction (PCR) and restriction fragment length polymorphism (RFLP) assays. All analyses were performed blind with respect to subject characteristics. Haplotypes were confirmed by a second person not directly involved in the current study. A negative control without template DNA was included with each set of PCR-RFLP assays. The primers were designed from the published GC gene sequence. ${ }^{22}$ The sense oligonucleotide primer (5'TATGATCTCGAAGAGGCATG-3') was designed from intron 10 and the antisense primer (5'-AATCACAGTAAAGAGGAGGT$\left.3^{\prime}\right)$ was designed from exon 11 ; the PCR product contained both single nucleotide polymorphisms (SNPs). The primers produced an amplified product of 328 base pairs (bp). PCR was carried out in a $20 \mu \mathrm{l}$ volume reaction mixture containing $200 \mathrm{ng}$ genomic DNA, 0.75 units Taq DNA polymerase (Gibco BRL, Grand Island, NY), $2.5 \mathrm{mM} \mathrm{MgCl}_{2}, 0.5 \mu \mathrm{M}$ of each primer, and $200 \mu \mathrm{M}$ each of deoxyguanosine triphosphate (dGTP), deoxycytidine triphosphate (dCTP), deoxythymidine triphosphate (dTTP), and deoxyadenosine triphosphate (dATP). Amplification conditions were as follows: an initial denaturation step at $94^{\circ} \mathrm{C}$ for 2 minutes, 40 cycles of $94^{\circ} \mathrm{C}$ (denaturation) for 30 seconds, $57^{\circ} \mathrm{C}$ (annealing) for 30 seconds, $72^{\circ} \mathrm{C}$ (elongation) for 45 seconds, followed by one cycle of elongation at $72^{\circ} \mathrm{C}$ for 5 minutes. Restriction enzyme digestions were accomplished by separately incubating the equally divided PCR product at $37^{\circ} \mathrm{C}$ for at least 2 hours with

\begin{tabular}{|c|c|c|c|}
\hline & $1 \mathrm{~S}$ & $1 F$ & 2 \\
\hline Total $(n=1070)$ & 0.55 & 0.15 & 0.30 \\
\hline High $(n=537)$ & 0.54 & 0.16 & 0.30 \\
\hline Low $(n=533)$ & 0.55 & 0.15 & 0.30 \\
\hline Previous study (white subjects) ${ }^{23}$ & 0.56 & 0.16 & 0.28 \\
\hline
\end{tabular}

10 units of either Hae III or Sty I restriction enzymes (New England Biolabs, Missisauga, Ontario). Hae III enzyme produced cut bands of 235 and $93 \mathrm{bp}$ if the 1s allele was present. Sty I enzyme cut the two allele producing bands of 242 and $86 \mathrm{bp}$. The $\mathrm{IF}$ variant remained as an uncut $328 \mathrm{bp}$ band in both enzyme digestions. Digested PCR products were loaded onto $2 \%$ agarose gels stained with ethidium bromide and visualised in ultraviolet illumination.

\section{Statistical analysis}

The results are presented as haplotype and allele frequencies for both high and low lung function groups. The differences in haplotype and allele frequency between the two groups were assessed by $\chi^{2}$ tests. The associations were also analysed by logistic regression to adjust for potential confounding factors-age, sex, smoking history (pack years), and rate of decline in lung function (percentage predicted $\mathrm{FEV}_{1}$ ). All tests were performed using the JMP Statistics software package (SAS Institute Inc). $p$ values of $<0.05$ were considered to be statistically significant. All values are expressed as mean (SE).

\section{RESULTS}

The characteristics of the 1070 white subjects are shown in table 1 . The mean level of $\mathrm{FEV}_{1} \%$ predicted was $91.8(0.1)$ in the high lung function group and $62.6(0.1)$ in the low lung function group. There were significant differences in age, smoking history, and rate of decline in lung function between the two groups so the final results were adjusted by logistic regression. The frequencies of the three GC haplotypes are shown in table 2 . These haplotype frequencies are similar to the distributions reported from large population studies. ${ }^{23}$ However, there was no difference in haplotype frequency between the high and low lung function groups. The frequencies of the six haplotype combinations are presented in table 3. There were no significant differences in haplotype combinations between the two groups $(p=0.24)$.

We also specifically analysed the contribution of $1 F$ and 2 haplotypes. Previous studies have shown that the $\mathrm{IF}$ haplotype confers susceptibility to COPD whereas the 2 haplotype confers protection from COPD. ${ }^{14-17}$ In each phenotypic group IF carriers were compared with IF non-carriers and 2 haplotype carriers were compared with 2 non-carriers, 
Table 3 Haplotype frequency in the high and low lung function groups

\begin{tabular}{lllllll}
\hline Group & $1 \mathrm{~F}-1 \mathrm{~F}$ & $1 \mathrm{~F}-2$ & $1 \mathrm{~F}-1 \mathrm{~S}$ & $1 \mathrm{~S}-1 \mathrm{~S}$ & $1 \mathrm{~S}-2$ & $2-2$ \\
\hline High & $13(2.4)$ & $60(11.2)$ & $89(16.6)$ & $158(29.4)$ & $176(32.8)$ & $41(7.6)$ \\
Low & $8(1.5)$ & $43(8.1)$ & $101(19.0)$ & $162(30.4)$ & $165(31.0)$ & $54(10.1)$ \\
\hline
\end{tabular}

Data are shown as number $(\%)$.

$p=0.24$.

Table 4 Power calculations for a sample size of $n=533$ cases and 537 controls with $\alpha=0.05$ and $\beta=0.80$ for a two sided test

\begin{tabular}{lll}
\hline $\begin{array}{l}\text { Prevalence of } \\
\text { polymorphism* }\end{array}$ & $\begin{array}{l}\text { Minimum detectable } \\
\text { RR (susceptive) }\end{array}$ & $\begin{array}{l}\text { Minimum detectable } \\
\text { RR (protective) }\end{array}$ \\
\hline $5 \%$ & 1.89 & 0.37 \\
$10 \%$ & 1.58 & 0.54 \\
$20 \%$ & 1.35 & 0.68 \\
$30 \%$ & 1.27 & 0.75 \\
$40 \%$ & 1.21 & 0.79 \\
$50 \%$ & 1.17 & 0.83 \\
\hline
\end{tabular}

*Individuals who have either one or two copies of the putative risk allele.

$\mathrm{RR}=$ relative risk

but we found no significant differences between the two groups for either the IF or 2 haplotype carriers (data not shown).

These haplotypes are constructed by the combination of two SNPs. We therefore also investigated each SNP separately to analyse the contribution of each to the level of lung function. No significant differences in genotype frequency were found between each group in either polymorphic site (data not shown). The overall observed distribution of homozygotes and heterozygotes for both polymorphisms did not differ from that predicted by the Hardy-Weinberg equilibrium.

\section{DISCUSSION}

Several studies have investigated the contribution of GC haplotypes to the pathogenesis of COPD in white populations. The first report was published in 1977 by Kueppers and coworkers $^{16}$ and showed that GC 2-2 homozygotes were less frequent in patients with COPD $(\mathrm{n}=114)$ than in controls (relative risk (RR) 0.2). In 1983 Kauffmann and coworkers ${ }^{18}$ also investigated the contribution of $G C$ haplotypes by comparing individuals with low $\mathrm{FEV}_{1}$ values who had never smoked $(n=43)$ and individuals with high $\mathrm{FEV}_{1}$ values who were heavy smokers $(n=45)$. They found no significant differences between these two groups for any haplotype. In 1990 Horne and coworkers ${ }^{14}$ found that homozygosity for the GC 2 haplotype and the presence of at least one GC 2 haplotype decreased the relative risk of developing COPD (RR 0.8 and 0.7 , respectively). They also found that homozygous $1 \mathrm{~F}-1 \mathrm{~F}$ individuals are at increased risk of developing COPD (RR 4.8). Most recently, Ishii et al ${ }^{15}$ showed that the $1 \mathrm{~F}-1 \mathrm{~F}$ genotype was associated with COPD in a Japanese population.

Although several reports have shown an association between GC haplotypes and COPD, the biological mechanism for these associations has not been sufficiently investigated. We showed that homozygosity for the GC 2 allele was protective against COPD, and also examined whether the association of GC haplotype with COPD could be caused by the effect of GC on neutrophil chemotaxis. ${ }^{17}$ However, we did not find any significant differences in chemotactic rates among the three GC isoforms. This result suggested that an alternative explanation must underlie our result. Besides increasing neutrophil chemotaxis, GC increases the activation of macrophages at sites of inflammation. ${ }^{12}$ Conversion of GC to a MAF is accomplished by the removal of specific glycosylated moieties from the protein. The moieties are cleaved by glycosidases present on both $\mathrm{B}$ and $\mathrm{T}$ cells. Interestingly, the glycoside side chain structure varies among isoforms. Both the $\mathrm{IS}$ and $\mathrm{IF}$ isoforms contain identical side chain structures, while the GC 2 isoform has alternate sugar moieties. The GC 2 protein is found in two different forms. The less prevalent form $(10 \%)$ displays a shorter side chain that needs only to be modified by $\mathrm{T}$ cells to become a MAF. ${ }^{12}$ The remaining $90 \%$ of the GC 2 protein molecules undergo no glycosylation and are incapable of being converted to a $\mathrm{MAF}^{12}$ consistent with a protective effect of this isoform.

The purpose of our current work was to determine the contribution of GC haplotypes to reduced maximal lung function or earlier onset of decline in lung function. We reasoned that these would be evident as a low level of lung function at the start of the Lung Health Study. This would not necessarily be associated with a fast rate of decline, thus explaining the lack of association in our previous study of participants in the Lung Health Study. ${ }^{20}$ The rate of decline in lung function and the level of lung function at a particular time point are obviously related variables. We therefore used logistic regression to adjust our results for the potentially confounding effects of rate of decline in lung function. In this study we were able to detect variation in the level of lung function that was not due to rate of decline and was presumably therefore due to either reduced maximal lung function or an earlier onset of decline. Our current study did not find any contribution of GC haplotype to level of lung function and, thus, could not support the previous positive findings. However, we believe that our current study provides meaningful information for future studies because of the high power of the study design. We estimated that, with our sample size $(n=1070)$, considering individuals with either one or two copies of a haplotype, we could detect an association with an RR of $\geqslant 1.27$ for the $\mathrm{IF}$ susceptibility haplotype or $\leqslant 0.83$ for the 2 protective haplotype, with $\alpha=0.05$ and $\beta=0.80$ (table 4 ).

The reason for the lack of replication of previous associations with GC haplotypes may relate to the different means of identification. The other studies used COPD patients and unaffected controls and therefore may have involved more individuals from the extremes of the susceptibility spectrum. This could have the effect of highlighting any genetic component to COPD susceptibility.

In summary, we found no significant differences in GC haplotype or genotype frequencies between high and low lung function groups. We conclude that the early onset of decline in lung function or reduced maximal lung function were not affected by $G C$ haplotype in this cohort of individuals.

\section{ACKNOWLEDGEMENT}

The Lung Health Study was supported by contract N01-HR-46002 from the Division of Lung Diseases of the National Heart, Lung, and Blood Institute (NHLBI). The authors gratefully acknowledge the NHLBI for the recruitment and characterisation of this cohort. This study was supported by a grant from Canadian Institutes of Health Research.

Authors' affiliations

I Kasuga, P D Paré, J Ruan, A J Sandford, University of British Columbia McDonald Research Laboratories/iCAPTURE Center, St Paul's 
Hospital, Vancouver, BC, Canada

J E Connett, Division of Biostatistics, School of Public Health, University of Minnesota, MN, USA

N R Anthonisen, Faculty of Medicine, University of Manitoba, Winnipeg, MB, Canada

\section{REFERENCES}

1 Burrows B, Knudson RJ, Cline MG, et al. Quantitative relationships between cigarette smoking and ventilatory function. Am Rev Respir Dis 1977;115:195-205.

2 Fletcher C, Peto R. The natural history of chronic airflow obstruction. BM 1977;1:1645-8.

3 Silverman EK, Speizer FE. Risk factors for the development of chronic obstructive pulmonary disease. Med Clin North Am 1996:80:501-22.

4 Sandford AJ, Weir TD, Pare PD. Genetic risk factors for chronic obstructive pulmonary disease. Eur Respir J 1997; 10:1380-91.

5 Sakao S, Tatsumi K, Igari H, et al. Association of tumor necrosis factor alpha gene promoter polymorphism with the presence of chronic obstructive pulmonary disease. Am J Respir Crit Care Med 2001; 163:420-2.

6 Joos L, Mclntyre L, Ruan J, et al. Association of IL-1 beta and IL-1 receptor antagonist haplotypes with rate of decline in lung function in smokers. Thorax 2001:56:863-6.

7 Kew RR, Webster RO. Gc-globulin (vitamin D-binding protein) enhances the neutrophil chemotactic activity of $\mathrm{C} 5 \mathrm{a}$ and $\mathrm{C} 5 \mathrm{a}$ des Arg. J Clin Invest 1988;82:364-9

8 Piquette CA, Robinson-Hill R, Webster RO. Human monocyte chemotaxis to complement-derived chemotaxins is enhanced by Gc-globulin. J Leukoc Biol 1994:55:349-54.

9 Ozaki T, Hayashi H, Tani K, et al. Neutrophil chemotactic factors in the respiratory tract of patients with chronic airway diseases or idiopathic pulmonary fibrosis. Am Rev Respir Dis 1992;145:85-91.

10 Krug N, Tschernig T, Erpenbeck VJ, et al. Complement factors C3a and C5a are increased in bronchoalveolar lavage fluid after segmental allergen provocation in subjects with asthma. Am J Respir Crit Care Med 2001;164:1841-3.

11 Metcalf JP, Thompson AB, Gossman GL, et al. Gc globulin functions as a cochemotaxin in the lower respiratory tract. A potential mechanism for lung neutrophil recruitment in cigarette smokers. Am Rev Respir Dis $1991 ; 143: 844-9$.
12 Yamamoto N, Homma S. Vitamin D3 binding protein (group-specific component) is a precursor for the macrophage-activating signal factor from lysophosphatidylcholine-treated lymphocytes. Proc Natl Acad Sci USA 1991:88:8539-43.

13 Kamboh MI, Ferrell RE. Ethnic variation in vitamin D-binding protein $(G C)$ : a review of isoelectric focusing studies in human populations. Hum Genet 1986;72:281-93.

14 Horne SL, Cockcroft DW, Dosman JA. Possible protective effect against chronic obstructive airways disease by the GC2 allele. Hum Heredity 1990:40:173-6.

15 Ishii T, Keicho N, Teramoto S, et al. Association of Gc-globulin variation with susceptibility to COPD and diffuse panbronchiolitis. Eur Respir J 2001;18:753-7.

16 Kueppers F, Miller RD, Gordon H, et al. Familial prevalence of chronic obstructive pulmonary disease in a matched pair study. Am J Med 1977:63:336-42.

17 Schellenberg D, Pare PD, Weir TD, et al. Vitamin D binding protein variants and the risk of COPD. Am J Respir Crit Care Med 1998;157:957-61.

18 Kauffmann F, Kleisbauer JP, Cambon-De-Mouzon A, et al. Genetic markers in chronic air-flow limitation. A genetic epidemiologic study. Am Rev Respir Dis 1983;127:263-9.

19 Tager IB, Segal MR, Speizer FE, et al. The natural history of forced expiratory volumes. Effect of cigarette smoking and respiratory symptoms. Am Rev Respir Dis 1988;138:837-49.

20 Sandford AJ, Chagani T, Weir TD, et al. Susceptibility genes for rapid decline of lung function in the lung health study. Am J Respir Crit Care Med 2001;163:469-73

21 Connett JE, Kusek JW, Bailey WC, et al. Design of the Lung Health Study: a randomized clinical trial of early intervention for chronic obstructive pulmonary disease. Control Clin Trials 1993;14:3-19S.

22 Braun A, Kofler A, Morawietz S, et al. Sequence and organization of the human vitamin D-binding protein gene. Biochim Biophys Acta 1993; 1216:385-94.

23 Gaensslen RE, Bell SC, Lee HC. Distributions of genetic markers in United States populations: III. Serum group systems and hemoglobin variants. J Forensic Sci 1987;32:1754-74. 